\title{
CHARACTERISTICS OF A POLYIMIDE MICROVALVE
}

\author{
Yu-Cheng Lin, Peter J. Hesketh, James G. Boyd ${ }^{+}$ \\ Center for Applications of Microfabrication in Manufacturing, \\ Department of Electrical Engineering and Computer Science, \\ ${ }^{+}$Department of Mechanical Engineering, \\ University of Illinois at Chicago, Chicago, Illinois 60607 \\ Susan M. Lunte*, and George S. Wilson* \\ *Center for Bioanalytical Research, University of Kansas, Lawrence, Kansas 66047
}

\begin{abstract}
A new micromachined microvalve has been designed and fabricated for a miniature micropump for nanodialysis[1]. Nanodialysis is an in vivo technique that permits continuous sampling of drugs and endogenous compounds in awake animals[2]. Twenty microvalves are fabricated on each 2 " silicon wafer. These microvalves have been integrated into a micropump for on-line nanodialysis.
\end{abstract}

\section{INTRODUCTION}

Micromachining and microfabrication techniques are now established processes for the fabrication of miniature sensors, microactuators, and microfabricated devices for microsystems.

More recently, micromachining techniques have been applied to the fabrication of chemical and biochemical sensors, and more significantly to micro chemical systems[3,4]. Micropumps and microvalves are one of the key elements in these analytical systems. Especially, microvalves play an important role for micropumps to function properly.

The microvalves can be categorized in two types: active and passive[5-20]. The passive microvalves are function as check valves. The valves open under forward applied pressure and have small leakage under backward applied pressure. The polyimide microvalve discussed in this paper is a passive microvalve.

\section{FABRICATION}

The cavities and channels are $50 \mu \mathrm{m}$ deep and made by anisotropic etching of silicon in $50 \% \mathrm{CsOH}$ at $60^{\circ} \mathrm{C}$ for 4.5 hours, using $\mathrm{SiO}_{2}$ masking layers on both sides of the wafer. The silicon wafer was anodically bonded to $2 \frac{1}{4}$ " diameter Pyrex glass disc by using $700-1000 \mathrm{~V}$ at $350^{\circ} \mathrm{C}$ in a nitrogen purged cabin to avoid oxidation of polyimide. The glass surface was damaged in the bonding process when using one contact point probe, however, there was no damage on the glass surface when using a gold coated surface beneath the contact. The glass opening is etched in 50\% $\mathrm{HF}$ with $\mathrm{Cr} / \mathrm{Au}$ masking layer to form the valves.

The polyimide microvalve, shown in Figure 1, has an opening diameter of $300 \mu \mathrm{m}$ and $50 \mu \mathrm{m}$ wide cross reinforcement strips.

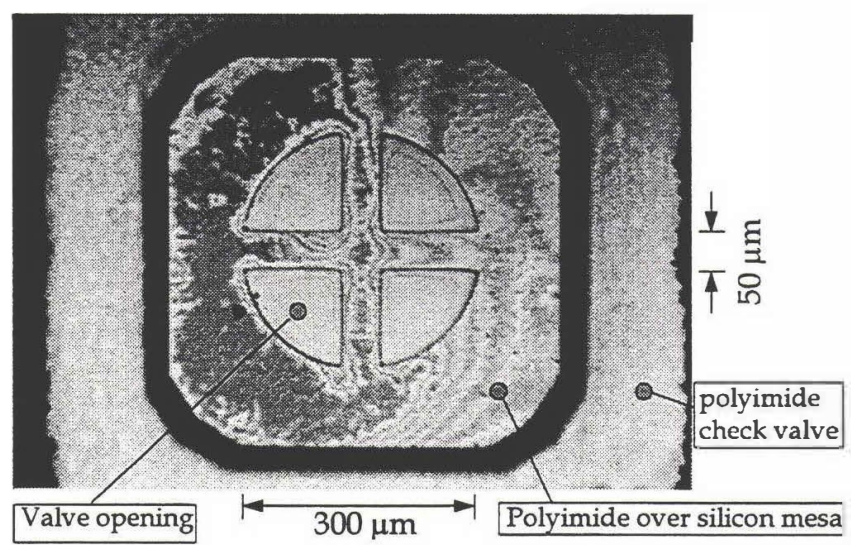

Figure 1. Photograph of the polyimide check valve with opening diameter of $300 \mu \mathrm{m}$ and $50 \mu \mathrm{m}$ wide cross reinforcement strips.

\section{EXPERIMENT}

The flow rate of the microvalve was measured by using the setup shown in Figure 2. The different applied pressures were obtained by changing the water height. The height remain the same by adding the DI water or alcohol with a syringe. The flow volume is obtained by scaling the syringe every five minutes. The pressure loss of this measurement setup has been calculated by using Poiseuille's equation and the Bernoulli equation for viscous flow, and found negligible compared to the applied pressure.

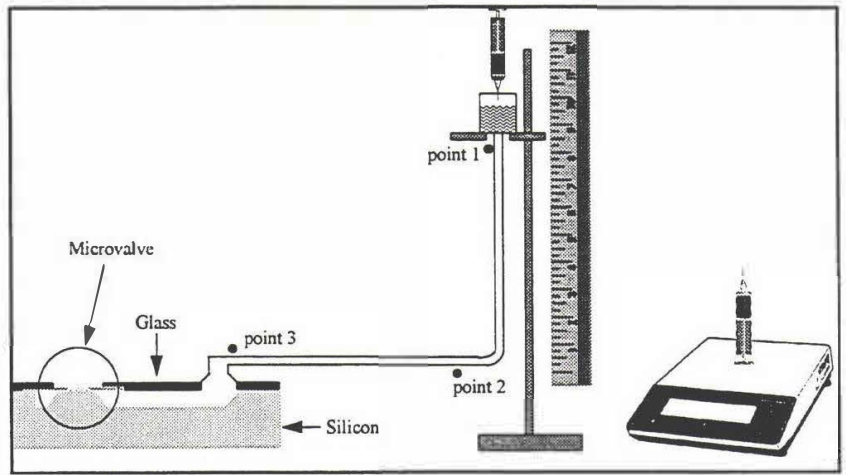

Figure 2. Schematic diagram of measurement setup for flow rate at different pressures. 
All valves tested show an aging effect. The fresh valve has a lower flow rate than after aging. Figure 3 shows the aging flow rates of DI water through a fresh $4.6 \mu \mathrm{m}$ thick polyimide check valve with two $50 \times 200 \times 1500 \mu \mathrm{m}$ channels under $20 \mathrm{~cm}-\mathrm{H}_{2} \mathrm{O}$ pressure at $22^{\circ} \mathrm{C}$.

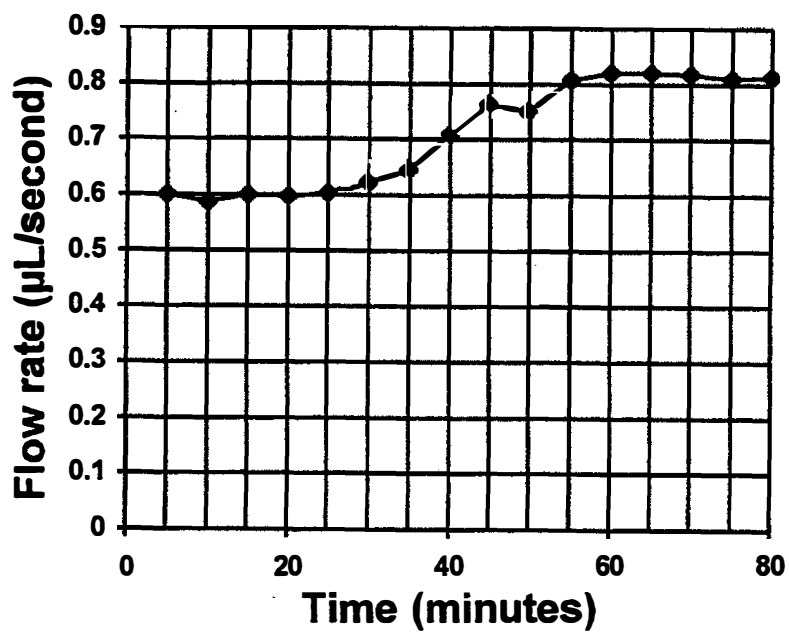

Figure 3. Valve aging and saturation with $20 \mathrm{~cm}-\mathrm{H}_{2} \mathrm{O}$ pressure applied. DI water flows through a fresh $4.6 \mu \mathrm{m}$ thick polyimide check valve with two $50 \times 200 \times 1500 \mu \mathrm{m}$ channels under $20 \mathrm{~cm}$ $\mathrm{H}_{2} \mathrm{O}$ pressure at $22^{\circ} \mathrm{C}$.

The first check valve was made with a $2.6 \mu \mathrm{m}$ thick layer of polyimide. The flow rates of DI water under different forward pressures through the $2.6 \mu \mathrm{m}$ thick polyimide check valve with a $58 \times 500 \times 1500 \mu \mathrm{m}$ channel are shown in Figure 4 .

The $4.6 \mu \mathrm{m}$ check valve is stronger than $2.6 \mu \mathrm{m}$ one for higher pressure applications. Figure 5 shows the flow rates of DI water through a $4.6 \mu \mathrm{m}$ thick check valve and two $50 \times 200 \times$ $1500 \mu \mathrm{m}$ channels at different forward pressures after aging. The dashed line indicates the flow rate is proportional to the applied pressure, and the minimum pressure to start flow is less than 5 $\mathrm{cm}-\mathrm{H}_{2} \mathrm{O}$ pressure.

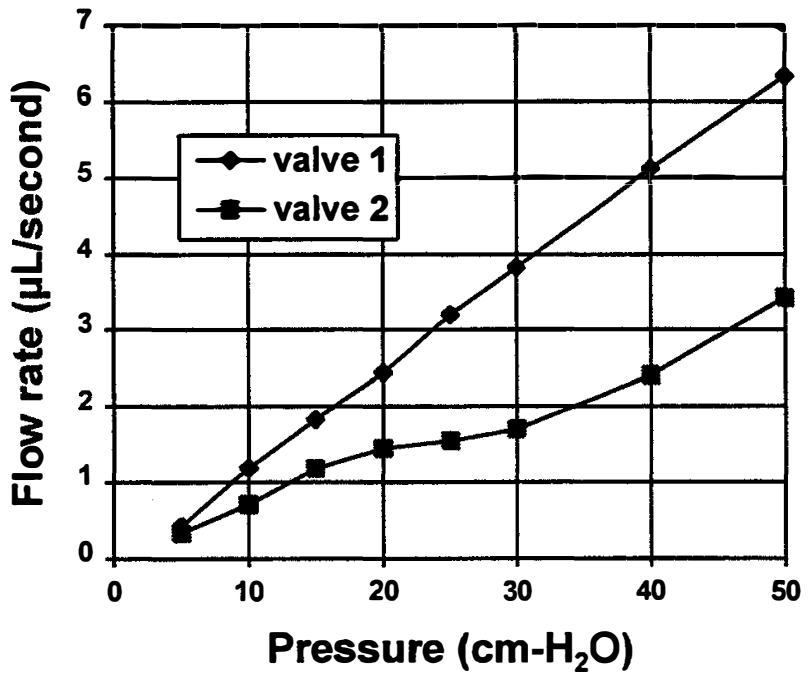

Figure 4. Comparison of the flow rates of DI water through two different $2.6 \mu \mathrm{m}$ thick check valves and the $58 \times 500 \times 1500 \mu \mathrm{m}$ channel under different forward pressures.

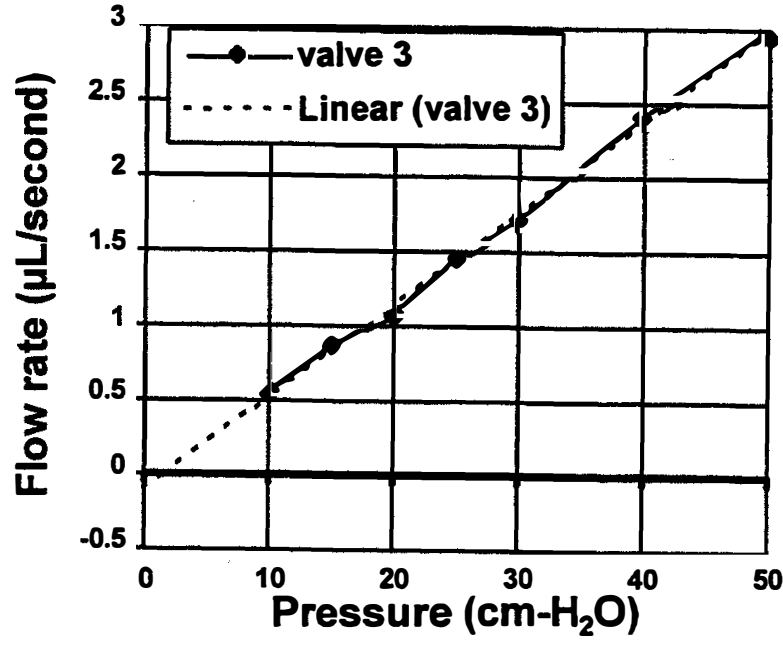

Figure 5. Flow rate of DI water through a $4.6 \mu \mathrm{m}$ thick check valve and two $50 \times 200 \times 1500 \mu \mathrm{m}$ channels at different forward pressures after aging.

The flow rate ratios of DI water for equal forward and backward pressures of the $4.6 \mu \mathrm{m}$ thick microvalve are above 200, shown in Figure 6.

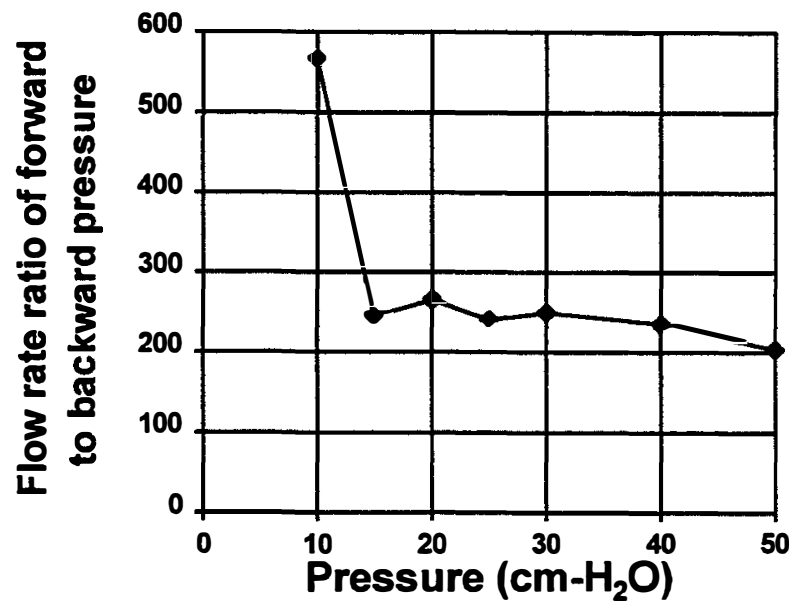

Figure 6. The ratio of flow rate of DI water for equal forward and backward pressures through a $4.6 \mu \mathrm{m}$ thick polyimide check valve and two $50 \times 200 \times 1500 \mu \mathrm{m}$ channels at $22^{\circ} \mathrm{C}$.

The flow rates of isopropyl alcohol through a $4.6 \mu \mathrm{m}$ check valve and three $50 \times 200 \times 1500 \mu \mathrm{m}$ channels under different forward pressures are shown in Figure 7. Each measurement is 5 minutes at $22^{\circ} \mathrm{C}$.

The isopropyl alcohol leakage through $4.6 \mu \mathrm{m}$ thick check valves with three $50 \times 200 \times 1500 \mu \mathrm{m}$ channels under different backward pressures are shown in Figure 8 . The dashed lines of the flow rates indicate the leakage is proportional to the applied pressure.

The ratios of flow rate of isopropyl alcohol for equal forward and backward pressure through a $4.6 \mu \mathrm{m}$ thick check valves with three $50 \times 200 \times 1500 \mu \mathrm{m}$ channels for valve 6 and valve 7 are less than 15:1. 


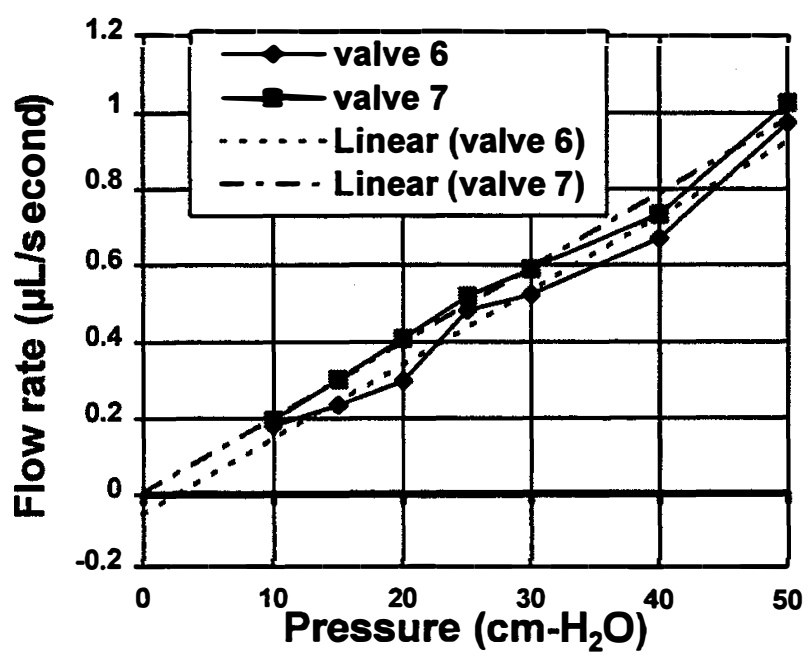

Figure 7. Comparison of two different $4.6 \mu \mathrm{m}$ check valves with isopropyl alcohol as the working fluid. The flow runs through a $4.6 \mu \mathrm{m}$ check valve and three $50 \times 200 \times 1500 \mu \mathrm{m}$ channels under different forward pressure.

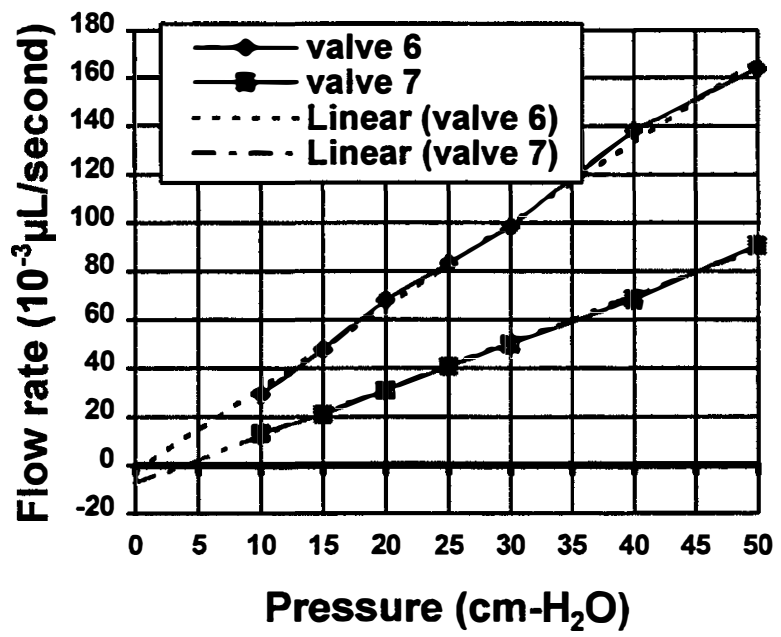

Figure 8. The isopropyl alcohol leakage through a $4.6 \mu \mathrm{m}$ check valve and three $50 \times 200 \times 1500 \mu \mathrm{m}$ channels under different back pressures. The dashed lines are linear and indicate the leakage is proportional to the pressure, and the minimum pressure to start leakage is less than $5 \mathrm{~cm}-\mathrm{H}_{2} \mathrm{O}$ pressure.

\section{CONCLUSIONS}

All valves have an aging effect. The fresh valve has a lower flow rate than after aging. The flow rate of this valve is proportional to the applied pressure, and the minimum pressure needed to start flow is quite small. The ratios of forward flow rate to backward leakage are above 200 with DI water as the working fluid. However, the ratios are less than 15 with isopropyl alcohol as the working fluid.

\section{REFERENCES}

1. Yu-Cheng Lin, Peter J. Hesketh, "A Micromachined Diaphragm Micropump", in Microstructures and Microfabricated Systems II, Proceedings of Electrochemical Society, Inc. p. 6772, Vol. 95-27, Pennington, NJ, 1995.

2. Barry L. Hogan and Susan M. Lunte, "On-line Coupling of In Vivo Microdialysis Sampling with Capillary Electrophoresis", Analytical-Chemistry, pp. 596-602, V66, N5, March, 1994.

3. S. C. Jacobson, R. Hergenroder, A. W. Jr. Moore, and J. M. Ramsey, "Precolumn reactions with electrophoretic analysis integrated on a microchip", Analytical Chemistry 66:4127-4132, 1994.

4. D. J. Harrison, K. Fluri, N. Chiem, T. Tang, and Z. Fan, "Micromachining chemical and biochemical analysis and reaction systems on glass substrates", Transducers '95, Eurosensors IX, pp. 752-755, 1995.

5. S. C. Terry, J. H. Jerman and J. B. Angell, "A gas chromatographic air analyzer fabricated on a silicon wafer", IEEE Trans. Electron Device, 26:1880-1886, 1979.

6. M. J. Zdeblick, and J. B. Angell, "A microminiature electric-to-fluidic valve", IEEE Technical Digest of Transducers, 87:827-929, 1987.

7. M. J. Zdeblick, R. Anderson, J. Jankowski, B. KlineSchoder, L. Christel, R. Miles, and W. Weber, "Thermopneumatically actuated microvalves and integrated electro-fluidic circuits", Technical Digest IEEE Solid-State Sensors and Actuator Workshop, pp. 251-255, 1994.

8. S. Shoji, M. Esashi, and M. Matsuo, "Prototype miniature blood gas analyzer fabricated on a silicon wafer", Sensors and Actuators 14:101-107, 1988.

9. M. Esashi, "Integrated microflow control systems", Sensors and Actuators A14-A23:161-167, 1990.

10. S. Shoji, and M. Esashi, "Micromachining for chemical sensors", Chem. Sensor Techn. 1:179-193, 1988.

11. T. Ohnstein, T. Fukiura, J. Ridley, and U. Bonne, "Micromachined silicon microvalve", Proc. IEEE Micro Electro Mechanical Systems Workshop, pp. 95-98, 1990.

12. H. Jerman, "Electrically-activated micromachined diaphragm valves", Technical Digest IEEE Sensors and Actuator Workshop, pp. 65-69, 1990.

13. K. Yanagisawa, H. Kuwano, and A. Tago, "An electromagnetically driven microvalve", IEEE Technical Digest of Transducers 93:102-105, 1993.

14. D. Bosch, B. Heimhofer, G. Muck, H. Seidel, U. Thumser, and Welser, W., "A silicon microvalve with combined electromagnetic/electrostatic actuation", Sensors and Actuators A37-A38:684-692, 1992. 
15. H. T. G. Van Lintel, and F. C. M. Van de Pol, "A piezoelectric micropump based on micromachining of silicon”, Sensors and Actuators 15:153-167,(1988.

16. J. Tiren, L. Tenerz, and B. Hok, “A batch-fabricated nonreverse valve with cantilever beam manufactured by micromachining of silicon",_Sensors and Actuators 18:389-396, 1989.

17. M. Esashi, S. Shoji, and A. Nakano, "Normally closed microvalve and micropump fabricated on a silicon wafer", Sensors and Actuators 20:163-167, 1989.
18. L. Smith, and B. Hok, "A silicon self-aligned non-reverse valve”, IEEE Technical Digest of Transducers, 1049-1051, 1991.

19. Schomburg and Scherrer, "3.5 $\mu \mathrm{m}$ thin valves in titanium membranes”, J. Micromech. Microeng. 2:184-186, 1992.

20. S. Shoji, M. Esashi, B. Schoot, and N. Rooij, "A study of a high-pressure micropump for integrated chemical analyzing systems", Sensors and Actuators A_32:335-339, 1992. 